\title{
Adubação química e cobertura morta em alho proveniente de cultura de tecidos
}

\author{
Tiago M. Correa ${ }^{1}$; Seneri K. Paludo ${ }^{1}$; Francisco V. Resende ${ }^{2}$; Paulo Sérgio R. de Oliveira ${ }^{1}$ \\ ${ }^{1}$ UNIMAR, FCA, C. Postal 554, 17525-902 Marília-SP.; ${ }^{2}$ Embrapa Hortaliças, C. Postal 218, 70359-970 Brasília-DF; Email: \\ correatm@hotmail.com
}

\begin{abstract}
RESUMO
Avaliou-se diferentes épocas de parcelamento da adubação de cobertura com nitrogênio e potássio e o uso de cobertura morta em um clone da cultivar Gravatá proveniente de cultura de tecidos. O delineamento experimental foi de blocos casualizados em esquema fatorial 2 × 3 com quatro repetições. Os tratamentos foram constituídos por solo com e sem cobertura morta e pela adubação de cobertura com N e K parcelada em três períodos de aplicação 45 e 65; 60 e $80 ; 75$ e 95 dias após o plantio. A altura das plantas, número de folhas/planta, diâmetro do bulbo e a taxa de bulbificação foram avaliados 105 dias após o plantio. O parcelamento da adubação com nitrogênio e potássio em cobertura na cultura do alho aos 45 e 65 dias ou aos 60 e 80 dias após o plantio resultaram em bulbos com maior diâmetro, independente do uso de cobertura morta. As demais características avaliadas não foram influenciadas pelas épocas de parcelamento da adubação nitrogenada e potássica. A cobertura morta mostrou-se vantajosa em relação ao solo descoberto para cultura do alho oriundo de cultura de tecidos, permitindo aumentos significativos no crescimento e produtividade, que alcançou 16,76 t/ha com cobertura e 13,44 t/ha sem cobertura.
\end{abstract}

Palavras-chave: Allium sativum L., cobertura do solo, nitrogênio, potássio, adubação de cobertura.

\begin{abstract}
Effect of chemical fertilization and mulching on growth and yield of garlic from tissue culture

This experiment was carried out at Marília, São Paulo state, Brazil, to evaluate the effect of soil mulching and side dressing fertilization using nitrogen and potassium on a garlic clone, cultivar Gravatá, originated from tissue culture. The experimental design was randomized blocks, in factorial scheme $2 \times 3$ with four replications. $\mathrm{N}$ and $\mathrm{K}$ were applied twice using three periods 45 and 70; 60 and 80; 75 and 95 days after planting with and without mulching. The plant height, number of leaves per plant, bulb diameter and bulbing ratio were measured 105 days after planting. Higher diameters of bulb were obtained with $\mathrm{N}$ and $\mathrm{K}$ applied 45 and 65 or 60 and 80 days after planting with and without mulching application. Periods of $\mathrm{N}$ and $\mathrm{K}$ parceling did not have any effect on the evaluated traits. The use of soil mulch resulted in higher growth and yield of garlic obtained from tissue culture, reaching $16.76 \mathrm{t} / \mathrm{ha}$ with mulching and $13.44 \mathrm{t} /$ ha without mulching.
\end{abstract}

Keywords: Allium sativum L., mulching, nitrogen, potassium, cover fertilization.

\section{(Recebido para publicação em 28 de julho de 2002 e aceito em 8 de setembro de 2003)}

\begin{abstract}
A partir do final da década de 70 houve um grande avanço no desenvolvimento de tecnologias para o cultivo do alho, quando o governo brasileiro criou o Programa Nacional de Produção e Abastecimento do Alho (PLANALHO), permitindo a diversificação, expansão e melhoria da sua qualidade (Camargo Filho et. al., 1999). Neste período houve aumentos, tanto na área quanto na produtividade que passou de 3,5 t/ha em 1978 para 6,23 t/ha nos dias atuais. Mas essa produtividade ainda é baixa quando comparada com os principais países exportadores para o Brasil, como por exemplo da Espanha (7,7 t/ha), da Argentina (9,50 t/ha) e da China (13,40 t/ha) (FAO, 2001). Portanto, o desafio da competitividade e da auto-suficiência da alhicultura nacional permanece atual.
\end{abstract}

O alho propagado de forma assexuada pode disseminar patógenos, principalmente vírus, que provoca degenerescência generalizada dos clones comerciais. Esse problema pode ser minimizado empregando-se a técnica da cultura de meristemas (Walkey et al., 1987; Verbeek et al., 1995) que proporciona plantas isentas de patógenos, com melhor desenvolvimento vegetativo e maior produção comercial de bulbos (Resende et al., 1995).

Em clones provenientes de cultura de tecidos podem ocorrer mudanças quantitativas e qualitativas na exigência nutricional, em função de alterações no desenvolvimento e na produtividade das plantas (Resende et al., 1999b).

O nitrogênio, potássio e fósforo têm mostrado efeitos significativos na altura da planta, no número de folhas e de bulbilhos, tamanho do bulbo e na produtividade (Souza \& Casalli, 1986). A resposta do alho à adubação potássica tem sido menos evidente do que à nitrogenada, em função do $\mathrm{K}$ ser retido no solo na sua forma trocável e de ocorrer menos perda por lixiviação que o nitrato (Coutinho et al., 1993; Machado, 2000). A resposta do alho a estes dois nutrientes acompanha o crescimento e desenvolvimento da cultura, intensificando durante o período de bulbificação (Silva et al., 1970; Zink, 1963). Parcelamentos da adubação de cobertura até 70 dias após o plantio tem resultado em aumento de produtividade. Aplicações mais tardias, principalmente, em cultivares suscetíveis ao superbrotamento podem reduzir a produção comercial (Resende \& Souza, 2001).

$\mathrm{O}$ alho obtido in vitro, por cultura de meristema responde melhor a níveis de $\mathrm{N}$ que o mesmo material multiplicado de forma convencional (Resende $e t$ 
al. 2000). Entretanto para o K, os materiais provenientes de cultura de tecidos não apresentaram respostas consistentes (Silva et al., 2000).

O uso de cobertura morta de solo é uma prática bastante tradicional na cultura do alho (Oliveira et al., 1986), principalmente entre os pequenos produtores. Em lavouras extensivas e mecanizadas essa prática foi abandonada devido à elevação de custos, principalmente, pela necessidade de mão de obra, obtenção e aplicação do material palhoso. O seu emprego traz vantagens como controle do regime térmico e hídrico do solo e redução da erosão (Singer et al., 1981; Bragagnolo \& Mielniczuck, 1990; Alves et al., 1995). O controle de plantas daninhas e redução de perdas de nutrientes por lixiviação também têm sido associados ao uso de cobertura morta de solo (Carter \& Johnson, 1988).

No presente trabalho determinou-se as épocas de parcelamento mais adequadas para aplicação de nitrogênio e potássio em cobertura na cultura do alho proveniente de cultura de tecidos, em sistemas de produção com e sem utilização de cobertura morta.

\section{MATERIAL E MÉTODOS}

O experimento foi instalado em campo na UNIMAR de abril a setembro de 1999, em Argissolo Vermelho Amarelo com as seguintes características químicas na camada de $0-20 \mathrm{~cm}: \mathrm{pH}\left(\mathrm{CaCl}_{2}\right)$ $=6,2 ;$ matéria orgânica $=20,8 \mathrm{~g} / \mathrm{dm}^{3} ; \mathrm{P}$ $=121 \mathrm{mg} / \mathrm{dm}^{3} ; \mathrm{K}=5,1 \mathrm{mmol} / \mathrm{dm}^{3} ; \mathrm{Ca}$ $=43 \mathrm{mmol} / \mathrm{dm}^{3} ; \mathrm{Mg}=26 \mathrm{mmol}_{\mathrm{c}} / \mathrm{dm}^{3}$; $\mathrm{V}=82 \%$.

O clone da cultivar Gravatá foi obtido por micropropagação in vitro via cultura de meristema, visando obtenção de plantas livres de vírus, e multiplicado por quatro gerações em condições de campo. Mesmo exposto a condições de reinfecção, seu uso ainda se justifica, pois a degenerescência causada por vírus na cultura do alho ocorre lentamente, mesmo em condições de alta pressão de inóculo (Resende \& Souza, 1998; Silva et al., 2002).

A cultivar Gravatá pertence ao grupo dos alhos de ciclo médio (5 a 6 meses) ou semi nobres, com pequena inci- dência de "palitos" (bulbilhos com dimensões inferiores a 5 x $17 \mathrm{~mm}$ ), resistência a pseudoperfilhamento e adaptação às condições climáticas das regiões Sudeste e Centro-oeste do país, dispensando a vernalização dos bulbos no préplantio (Embrapa, 1997).

Foram estabelecidos seis tratamentos, a partir de um fatorial $2 \times 3$, em delineamento experimental de blocos casualizados com quatro repetições. $\mathrm{O}$ primeiro fator constituiu-se do uso ou não de cobertura morta. $\mathrm{O}$ segundo fator foi constituído por três períodos de adubação com $\mathrm{N}$ e $\mathrm{K}$ em cobertura, parcelados em duas aplicações aos $45 \mathrm{e}$ 65 dias após o plantio (DAP), 60 e 80 DAP, 75 e 95 DAP.

As adubações de plantio, conforme Raij et al. (1996), foram: $20 \mathrm{~kg} / \mathrm{ha}$ de $\mathrm{N}$ (uréia), $240 \mathrm{~kg} /$ ha de $\mathrm{P}_{2} \mathrm{O}_{5}$ (superfosfato simples), $120 \mathrm{~kg} /$ ha de $\mathrm{K}_{2} \mathrm{O}$ (cloreto de potássio), $5 \mathrm{~kg} / \mathrm{ha} \mathrm{Zn}$ (sulfato de zinco), $3 \mathrm{~kg} /$ ha de B (bórax). Em cobertura aplicou-se $80 \mathrm{~kg} / \mathrm{ha}$ de $\mathrm{N}$ e $40 \mathrm{~kg} / \mathrm{ha}$ de $\mathrm{K}_{2} \mathrm{O}$, com as mesmas fontes anteriores, parcelados de acordo com os tratamentos deste trabalho.

O plantio foi realizado em canteiros com $20 \mathrm{~cm}$ de altura e um metro de largura, em sulcos com $5 \mathrm{~cm}$ de profundidade espaçados de $20 \mathrm{~cm}$, longitudinais ao canteiro. Bulbilhos retidos nas penei$\operatorname{ras} 2(10 \times 20 \mathrm{~mm})$ e $3(8 \times 17 \mathrm{~mm})$ foram colocados em sulcos, distanciados $10 \mathrm{~cm}$, de modo a obter população de 50 plantas $/ \mathrm{m}^{2}$. As parcelas mediram 1,5 $\mathrm{m}$ de comprimento com cinco linhas de plantio. A área útil $\left(0,66 \mathrm{~m}^{2}\right)$ da parcela foi delimitada descartando-se como bordadura, uma linha nas laterais dos canteiros e duas plantas das linhas nas extremidades das parcelas.

O controle de plantas espontâneas foi realizado com tratamento pré emergente, utilizando o herbicida Linuron em conjunto com capinas manuais. Como cobertura morta utilizou-se uma camada de 5 $\mathrm{cm}$ de espessura de serragem de madeira, mantida até o final do ciclo da cultura.

$\mathrm{O}$ diâmetro do bulbo e a taxa de bulbificação foram avaliados com auxílio de paquímetro aos 105 dias após o plantio. A taxa de bulbificação ou razão bulbar foi obtida pela relação entre o diâmetro do bulbo e do pseudocaule (Mann, 1952).
As plantas foram colhidas quando verificou-se a senescência da parte aérea, com 165 dias de idade. Após a colheita os bulbos foram secados ao sol durante três dias e curados na sombra em local ventilado por 30 dias. Ao final deste período foram realizadas avaliações de produção total, produção comercial, peso médio de bulbos, peso médio de bulbilhos e número de bulbilhos por bulbo.

Os dados obtidos foram submetidos a testes de normalidade e homogeneidade de variâncias (Little \& Hills, 1978) como pré-condição para a análise de variância utilizando-se o teste F de Snedecor. Para análise dos contrastes de médias usou-se o teste Tukey com 5\% de probabilidade (Gomes, 1990).

\section{RESULTADOS E DISCUSSÃO}

A interação entre a utilização ou não de cobertura morta para o solo e a época de aplicação da adubação de cobertura não foi significativa, mostrando independência entre estes fatores nas condições experimentais deste trabalho.

Não foi constatada diferença estatística entre os tratamentos para razão bulbar, embora se tenha observado uma tendência de superioridade para a altura de planta e o número de folhas das duas primeiras épocas de adubação em relação à terceira. Para o diâmetro do bulbo a aplicação de N e K em cobertura aos 60 e 80 DAP foi semelhante à recomendação usual (45 e 65 DAP), mas significativamente superior à época de 75 e 95 DAP (Tabela 1).

O fato de não se observar diferenças significativas entre os tratamento para altura de plantas e número de folhas são explicados pelas curvas de crescimento do alho. Em algum momento entre 100 e 120 dias após o plantio, dependendo da cultivar, o desenvolvimento da parte aérea tende a estabilizar-se, enquanto as diferenças para o diâmetro do bulbo justificam-se pela intensificação da bulbificação até a completa maturação dos bulbos, concomitantemente acompanhada pela absorção de nutrientes (Zink, 1963; Silva et al., 1970; Lisbão et. al., 1991; Resende et al. 1999b).

Para a razão bulbar os tratamentos mostraram-se estatisticamente iguais 
Tabela 1. Altura da planta, número de folhas por planta, diâmetro do bulbo e razão bulbar aos 105 dias após o plantio do alho cultivado em solo com e sem cobertura morta, submetido a diferentes épocas de aplicação de nitrogênio e potássio. Marília, UNIMAR, 1999.

\begin{tabular}{lcccc}
\hline $\begin{array}{c}\text { Época da adubação } \\
\text { (dias após o } \\
\text { plantio) }\end{array}$ & $\begin{array}{c}\text { Altura da planta } \\
\text { (cm) }\end{array}$ & $\begin{array}{c}\mathbf{N}^{\circ} \text { de folhas por } \\
\text { planta }\end{array}$ & $\begin{array}{c}\text { Diâmetro do bulbo } \\
\text { ( } m \text { m) }\end{array}$ & Razão bulbar \\
\hline 45 e 65 & $67,08 \mathrm{a}$ & $8,65 \mathrm{a}$ & $26,40 \mathrm{ab}$ & $0,52 \mathrm{a}$ \\
60 e 80 & $66,61 \mathrm{a}$ & $8,90 \mathrm{a}$ & $27,17 \mathrm{a}$ & $0,53 \mathrm{a}$ \\
75 e 95 & $64,48 \mathrm{a}$ & $8,47 \mathrm{a}$ & $23,57 \mathrm{~b}$ & $0,53 \mathrm{a}$ \\
\hline Com cobertura morta & $67,96 \mathrm{a}$ & $8,92 \mathrm{a}$ & $27,66 \mathrm{a}$ & $0,50 \mathrm{~b}$ \\
Sem cobertura morta & $64,14 \mathrm{~b}$ & $8,43 \mathrm{a}$ & $23,76 \mathrm{~b}$ & $0,55 \mathrm{a}$ \\
\hline C.V. $(\%)$ & 5,07 & 6,56 & 8,66 & 6,18 \\
\hline
\end{tabular}

Médias seguidas pelas mesmas letras, nas colunas, não diferem entre si pelo teste Tukey com $5 \%$ de probabilidade

Tabela 2. Peso médio de bulbos (g), produtividade total ( $/$ /ha) e comercial ( $\mathrm{t} / \mathrm{ha}$ ), número de bulbilhos por bulbo e peso médio de bulbilho (g) do alho cultivado em solo com e sem cobertura morta e com diferentes épocas de aplicação de nitrogênio e potássio. Marília, UNIMAR, 1999.

\begin{tabular}{lccccc}
\hline $\begin{array}{c}\text { Época da adubação } \\
\text { (dias após o } \\
\text { plantio) }\end{array}$ & $\begin{array}{c}\text { Peso médio } \\
\text { bulbo (g) }\end{array}$ & $\begin{array}{c}\text { Produtiv. total } \\
\text { (t/ha) }\end{array}$ & $\begin{array}{c}\text { Produtiv. } \\
\text { comercial (t/ha) }\end{array}$ & $\begin{array}{c}\mathbf{N}^{\circ} \\
\text { bulbilhos/bulbo }\end{array}$ & $\begin{array}{c}\text { Peso bulbilho } \\
\text { (g) }\end{array}$ \\
\hline 45 e 65 & $31,33 \mathrm{a}$ & $15,31 \mathrm{a}$ & $14,87 \mathrm{a}$ & $12,17 \mathrm{a}$ & $2,53 \mathrm{a}$ \\
60 e 80 & $32,50 \mathrm{a}$ & $15,33 \mathrm{a}$ & $14,89 \mathrm{a}$ & $11,93 \mathrm{a}$ & $2,70 \mathrm{a}$ \\
75 e 95 & $29,54 \mathrm{a}$ & $14,67 \mathrm{a}$ & $13,58 \mathrm{a}$ & $11,87 \mathrm{a}$ & $2,57 \mathrm{a}$ \\
\hline Com cobertura morta & $34,00 \mathrm{a}$ & $16,76 \mathrm{a}$ & $16,34 \mathrm{a}$ & $12,53 \mathrm{a}$ & $2,66 \mathrm{a}$ \\
Sem cobertura morta & $28,24 \mathrm{~b}$ & $13,44 \mathrm{~b}$ & $12,55 \mathrm{~b}$ & $11,45 \mathrm{~b}$ & $2,54 \mathrm{a}$ \\
\hline C.V. (\%) & 7,64 & 10,16 & 13,33 & 9,66 & 13,40 \\
\hline
\end{tabular}

Médias seguidas pelas mesmas letras, nas colunas, não diferem entre si pelo teste Tukey com $5 \%$ de probabilidade.

indicando aos 105 dias que os bulbos apresentavam o mesmo estágio de desenvolvimento e que as épocas de parcelamento da adubação de cobertura não influenciaram a velocidade de formação dos bulbos.

Pode-se observar que em função dos valores da razão bulbar estarem acima de 0,5 a formação do bulbo não havia ainda se completado em nenhum dos tratamentos (Mann 1952), na época em que foi avaliada. Como foi utilizado um clone oriundo de cultura de tecidos que apresenta ciclo mais longo do que aqueles mantidos em multiplicação convencional é esperado que ocorra algum atraso no processo de bulbificação deste material.

As características de peso médio de bulbos, produção total e comercial, número de bulbilhos por bulbo e peso médio de bulbilhos não diferiram estatisticamente (Tabela 2), embora os tratamentos onde a adubação de cobertura foi parcelada aos 60 e 80 ou 45 e 65 DAP, tenham apresentado uma tendên- cia de superioridade sobre a adubação de 75 e 95 DAP.

Considerando a maior demanda por nutrientes das plantas de alho oriundas de micropropagação (Resende et. al., 1999a; Resende et. al., 1999b), pode haver um melhor aproveitamento das adubações de cobertura realizada aos 60 e 80 DAP. Entretanto, deve-se ter em mente que aplicações muito tardias da adubação de cobertura podem afetar a qualidade dos bulbos e reduzir a produção comercial do alho (Resende \& Souza, 2001).

Os dados obtidos com a utilização da cobertura morta apresentaram resultados significativamente superiores aos mesmos tratamentos com o solo descoberto para altura da planta e diâmetro de bulbo (Tabela 1). No caso da razão bulbar, o valor para esta característica do tratamento com cobertura de solo foi significativamente inferior ao sem cobertura, indicando que esta prática pode influenciar a formação do bulbo na cultura do alho.
A utilização de cobertura morta propiciou maior produtividade e peso médio de bulbos, aumentou a produção comercial e o número de bulbilhos por bulbo (Tabela 2). A prática de cobrir o solo com materiais palhosos tem sido utilizada na cultura do alho, principalmente em pequenas áreas, com vantagens comprovadas (Oliveira et al., 1986; Sumi et al., 1986). A cobertura morta reduz a temperatura do solo, diminui a perda de água por evaporação e auxilia no controle de plantas daninhas (Oliveira et al., 1986). Em condições de umidade adequada no solo, o aproveitamento dos nutrientes torna-se mais eficiente, principalmente quando se refere ao nitrogênio que possui características altamente influenciadas pelas condições climáticas e pelo meio de cultivo.

Com base nos resultados obtidos pode-se concluir que, independente do uso de cobertura morta de solo, a aplicação de nitrogênio e potássio em cobertura na cultura do alho pode ser parcelada aos 45 e 65 dias ou aos 60 e 80 
dias após o plantio para clones de alho comum obtidos via cultura de tecidos. O uso de cobertura morta de solo é uma prática vantajosa inclusive para este tipo de alho, permitindo aumentos significativos no desenvolvimento e nas características produtivas da cultura.

\section{LITERATURA CITADA}

ALVES, A.G.C.; COGO, N.P.; LEVIEN, R. Relações da erosão do solo com a persistência da cobertura vegetal morta. Revista Brasileira de $\mathrm{Ci}$ ência do solo, Viçosa, v. 19, n. 1 p. 127-132, 1995. BRAGAGNOLO, N.; MIELNICZUK, J. Cobertura do solo por palha de trigo e seu relacionamento com a temperatura e umidade do solo. Revista Brasileira de Ciência do solo, Viçosa, v. 14, n. 3 p. 369-374, 1990.

CAMARGO FILHO, W.P.; MAZZEI, A.R.; ALVES, H.S. Concorrência da China e Argentina no mercado brasileiro de alho. Infornações Econômicas, São Paulo, v. 29, n. 10, p. 63-70, 1999. CARTER, I.; JOHNSON, C. Influence of different types of mulches on eggplant production. Hortscience, v. 10, n. 1, p. 143-145, 1988

COUTINHO, E.L.M.; NATALE, W.; SOUZA, E.C.A. Adubos e corretivos: aspectos particulares na olericultura. In: FERREIRA, M.E.; CASTELLANE, P.D.; CRUZ, M.C.P. Nutrição e adubação das hortaliças. Piracicaba: POTAFOS, 1993. p. 85-140

EMPRESA BRASILEIRA DE PESQUISA AGROPECUÁRIA - EMBRAPA. Cultivo do alho (Allium sativum). Brasília, Embrapa Hortaliças, 1997. 23 p. (Instrução Técnica, 2).

FAO (Roma, Italy). Agricultural production, primary crops-garlic. Disponível em $<$ http:// www.fao.org $>$ Consultado em 15/12/01.

GOMES, F.P. Curso de Estatística Experimental. Piracicaba:Nobel, 1990. 468 p.

LISBÃO, R.S.; TRANI, P.E., HIROCE, R.; FORNASIER, J.B. Crescimento e absorção de nutrientes pelo alho (Allium sativum L.), Roxo Pérola de Caçador, cultivado em condições de campo. Revista de Agricultura, v. 66, n. 3, p. 271295, 1991.
LitTle, T.M.; HILlS, F.J. Agricultural Experimentation, New York: John Willey and Sons, 1978, $350 \mathrm{p}$.

MACHADO, A.S. Efeito de doses de potássio (cloreto de potássio) em alho, cultivar Gravatá, proveniente de cultura de tecidos e propagação convencional. Lavras: UFLA, 2000, 27 p. (Tese mestrado)

MANN, L.K. Anatomy of the garlic bulb and factors affecting bulb development. Hilgardia, v. 21, n. 8. p. 195-251, 1952.

OLIVEIRA, A.P.; FERREIRA, F.A.; SOARES, J.G. Uso da cobertura morta no cultivo do alho. Informe Agropecuário, Belo Horizonte, v. 13, n. 142, p. 34-36, 1986.

RAIJ, B.V.; CANTARELLA, H.; QUAGGIO, J.A.; FURLANI, A.M.C. Boletim técnico 100: Recomendações de adubação e calagem para o estado de São Paulo. 2 ed., Campinas: IAC, 1996. $285 \mathrm{p}$.

RESENDE, F.V.; FAQUIN, V.; SOUZA, R.J.; SILVA, V.S. Acúmulo de matéria seca e exigências nutricionais de plantas de alho provenientes de cultura de tecidos e de propagação convencional. Horticultura Brasileira, Brasília, v. 17, n. 3, p. 220-226, 1999b.

RESENDE, F.V.; OLIVEIRA, P.S.R.; SOUZA, R.J. Crescimento, produção e absorção de nitrogênio do alho proveniente de cultura de tecidos, cultivado com doses elevadas de nitrogênio. Horticultura Brasileira, Brasília, v. 18, n. 1, p. 31-36, 2000.

RESENDE, F.V.; SOUZA, R.J. Degenerescência em clones de alho proveniente de cultura de tecidos após quatro multiplicações em condições de campo. Unimar Ciências, Marilia, v. 7, n. 2, p. 81-88, 1998.

RESENDE, F.V.; SOUZA, R.J.; FAQUIN, V.; RESENDE, J.T.V. Comparação do crescimento e produção entre alho proveniente de cultura de tecidos e de multiplicação convencional. Horticultura Brasileira, Brasília, v. 17, n. 2, p. 118-124, 1999a.

RESENDE, F.V.; SOUZA, R.J.; PASQUAL, M. Comportamento, em condições de campo, de plantas de alho obtidas por cultura de meristemas. Horticultura Brasileira, Brasília v. 13, n. 1, p. 4446, 1995.
RESENDE, G.M.; SOUZA, R.J. Doses e épocas de aplicação de nitrogênio sobre a produtividade e características comerciais do alho. Horticultura Brasileira, Brasília, v. 19, n. 2, p. 126-129, 2001. SILVA, E.C.; MACHADO, A.S.; SOUZA, R.J.; CALDERÓN, J.F.T. Efeitos de doses de potássio (cloreto de potássio) e nitrogênio (sulfato de amônio) em alho proveniente de cultura de tecidos. Ciência e Agrotecnologia, Lavras, v. 24, n. 4, p. 917-923, 2000.

SILVA, E.C.; SILVA, F.M.; SOUZA, R.J.; PASCAL, M. Estudo da degenerescência de clones de cultivares de alho provenientes de cultura de tecidos. Horticultura Brasileira, Brasília, v. 20, n. 2, 2002. Suplemento 2 .

SILVA, N.; OLIVEIRA, G.D.; VASCONCELOS, E.F.P.; HAAG, H.P. Absorção de nutrientes pela cultura do alho. O Solo, Piracicaba, v. 62, n. 1, p. 8-17, 1970.

SINGER, M.J.; MATSUDA, Y.; BLACKARD, J. Effect of mulch rate on soil loss by raindrop splash. Soil Science Society Of America Journal. v. 45, n. 1, p. 107-110, 1981.

SOUZA, R.J.; CASALI, V.W.D. Pseudoperfilhamento - uma anormalidade genético-fisiológica em alho. Informe Agropecuário, Belo Horizonte, v. 12, n. 142, p. 36-40, 1986.

SUMI, S.; CASTELLANE, P.; BELLINGIERI, P.; CHURATA-MASCA, M.G.C. Cobertura morta e doses de superfosfato simples na cultura do alho. Horticultura Brasileira, Brasilia, v. 4, n. 1, p. 32-34, 1986.

WALKEY, D.G.A.; WEBB, M.J.; BOLLAND, C.J., MILLER, A. Production of virus-free garlic (Allium sativum L.) and shallot (Allium ascalonicum L.) by meristem tip culture. The Journal of Horticultural Science, v. 82, n. 2, p. 211-220, 1987.

VERBEEK, M.; DIJK, P.V.; WELL, P.M.A. Efficiency or erradication of four viruses from garlic (Allium sativum L.) by meristem tip culture. European Journal of Plant pathology. v. 101, p. 131-139, 1995.

ZINK, K.F.W. Rate of growth and nutrient uptake and nutrient absorption of late garlic. Proceedings of American Society of Horticultural Science, v. 83 , p. $579-584,1963$. 